\title{
Finite element stress analysis of the bearing component and bone resected surfaces for total ankle replacement with different implant material combinations
}

Jian $\mathrm{Yu}^{1+}$, Dahang Zhao ${ }^{2 \dagger}$, Wen-Ming Chen ${ }^{3 \dagger}$, Pengfei Chu ${ }^{3}$, Shuo Wang ${ }^{1}$, Chao Zhang $^{1}$, Jiazhang Huang ${ }^{1}$, Xu Wang ${ }^{1}$ and Xin Ma ${ }^{1,3^{*}}$

\begin{abstract}
Background: A proper combination of implant materials for Total Ankle Replacement (TAR) may reduce stress at the bearing component and the resected surfaces of the tibia and talus, thus avoiding implant failure of the bearing component or aseptic loosening at the bone-implant interface.

Methods: A comprehensive finite element foot model implanted with the INBONE II implant system was created and the loading at the second peak of ground reaction force was simulated. Twelve material combinations including four materials for tibial and talar components (Ceramic, CoCrMo, Ti6AI4V, CFR-PEEK) and three materials for bearing components (CFR-PEEK, PEEK, and UHMWPE) were analyzed. Von Mises stress at the top and articular surfaces of the bearing component and the resected surfaces of the tibia and talus were recorded.

Results: The stress at both the top and articular surfaces of the bearing component could be greatly reduced with more compliant bearing materials (44.76 to $72.77 \%$ difference of peak stress value), and to a lesser extent with more compliant materials for the tibial and talar components (0.94 to $28.09 \%$ difference of peak stress value). Peak stresses at both the tibial and talar bone-implant interface could be reduced more strongly by using tibial and talar component materials with smaller material stiffness (7.31 to 66.95\% difference of peak stress value) compared with bearing materials with smaller material stiffness (1.11 to $24.77 \%$ difference of peak stress value).
\end{abstract}

Conclusions: Implant components with smaller material stiffness provided a stress reduction at the bearing component and resected surfaces of the tibia and talus. The selection of CFR-PEEK as the material of tibial and talar components and UHMWPE as the material of the bearing component seemed to be a promising material combination for TAR implants. Wear testing and long-term failure analysis of TAR implants with these materials should be included in future studies.

Keywords: Computational modeling, Finite element method, Implant design, Total ankle arthroplasty, Total ankle replacement, Implant material selection

\footnotetext{
*Correspondence: xin_ma@foxmail.com

${ }^{\dagger}$ Jian Yu, Dahang Zhao and Wen-Ming Chen contributed equally.

${ }^{3}$ Academy for Engineering and Technology, Fudan University, 220 Handan Lu, Shanghai, China

Full list of author information is available at the end of the article
}

\section{Introduction}

Total ankle replacement (TAR) has become an effective procedure for end-stage ankle arthritis which replaces damaged ankle with artificial implants to restore ankle function [1]. The early and midterm clinical results of original author(s) and the source, provide a link to the Creative Commons licence, and indicate if changes were made. The images or other third party material in this article are included in the article's Creative Commons licence, unless indicated otherwise in a credit line to the material. If material is not included in the article's Creative Commons licence and your intended use is not permitted by statutory regulation or exceeds the permitted use, you will need to obtain permission directly from the copyright holder. To view a copy of this licence, visit http://creativecommons.org/licenses/by/4.0/. The Creative Commons Public Domain Dedication waiver (http://creativeco mmons.org/publicdomain/zero/1.0/) applies to the data made available in this article, unless otherwise stated in a credit line to the data. 
new-generation ankle implants appear promising $[2,3]$. However, the implant survivor rate of TAR is not comparable with that of total knee arthroplasty (TKA) or total hip arthroplasty (THA) [4-7]. The common post-operative complication of TAR includes implant failure of the bearing component and aseptic loosening at the boneimplant interface [8-10]. The mechanism behind it is still unclear, and biomechanical factors may play an important role in the cause of these complications [11-13]. Therefore, it is needed to further understand the biomechanics of the TAR to help the design of new total ankle implants with improved clinical performance.

The materials selection for implant components are critical to implant design and proper material selection may avoid local excessive bone stress [14-16]. However, no consensus of the optimum material combination for total ankle implant has been reached [17]. Most existing total ankle implants used ultra-high molecular weight polyethylene (UHMWPE) as bearing material and metal (cobalt-chromium-molybdenum alloy (Co-Cr-Mo) or Titanium alloy (Ti6Al4V)) as the material of tibial or talar components. Only one TAR system chose to use ceramic as tibial and talar component material (TNK ankle, Kyocera, Kyoto, Japan) [18]. Polyether-ether-ketone (PEEK) and carbon-fiber-reinforced Polyether-etherketone (CFR-PEEK) have been used in joint replacement as a potential alternative to both the metal and bearing components $[19,20]$. However, studies about the biomechanics of the TAR implant with different materials are lacking.

Due to the difficulties in measuring the stress on the implant and bones, finite element (FE) simulation had been widely used for the pre-clinical biomechanical evaluation of orthopedic implants [21, 22] and a few FE studies tested the effect of implant material for TAR [12, 23-30]. Kerschhofer et al. [29] simulated contact stress and wear rate of PEEK and its composites on Wright State University (WSU) TAR devices. Through a tibial bone-implant construct of the STAR ankle system, Mondal et al. [14] investigated the relationship between implant materials and several biomechanical parameters (tibial strain, micromotion, and wear depth) in a FE hindfoot model. However, the above-mentioned studies only considered partial models of the foot. The load and boundary conditions were not realistic. Considering the complexity of ankle anatomy, a comprehensive foot model accounting for ligaments, cartilage, muscular force, and 28 bones of the foot and ankle may better recreate the biomechanics of the ankle in silico. Ozen et al. [31] first developed a FE model of the whole foot and ankle implanted with the Bueshel-Pappas implant system at a balance standing position to simulate the stress at each bone. More recently, Wang et al. [12,30] use a comprehensive FE foot model to compare the difference of the plantar pressure, joint contact pressure, the peak stress value among an intact foot, a foot with STAR ankle system, and a foot after ankle arthrodesis.

In this study, a comprehensive FE foot model implanted with an INBONE II implant system (Wright Medical Technology, Inc., Memphis, TN, US) was constructed to investigate the biomechanical impact of different implant material combinations on the stress distribution at the bearing component and the bone-implant interface. It was hypothesized that the material of components with smaller material stiffness may reduce the peak stress at their nearby surfaces. We chose to place this implant system into the intact FE foot model (see Fig. 1) since it is the only ankle implant system currently used in China. It has a medullar segmented stem, assembled with a tibial tray, and a symmetric fixed bearing component with full conformity to the talus component [32]. To the best of the authors' knowledge, no studies have previously investigated the biomechanical performance of this ankle system.

\section{Method}

\section{FE modeling of the foot and implant constructs}

The current FE model was modified from the model used in previous studies [33, 34]. All bones were connected by 134 major ligaments and a plantar fascia. The ligaments were represented by spring elements with a 'no compression' option. The 3D geometries of the plantar fascia and Achilles tendon were constructed. The other five muscle tendons, namely tibialis posterior (TIBP), flexor hallucis longus (FHL), flexor digitorum longus (FDL), peroneus brevis $(\mathrm{PB})$, and peroneus longus $(\mathrm{PL})$, were also incorporated into the model using bar elements, at their corresponding anatomical attachment sites.

The plantar soft tissue was modeled by an incompressible Ogden hyperelastic material [33]. The strain energy function $U$ of the first-order Ogden model was defined by:

$$
\mathrm{U}=\frac{2 \mu}{\alpha^{2}}\left(\lambda_{1}^{\alpha}+\lambda_{2}^{\alpha}+\lambda_{3}^{\alpha}-3\right)
$$

The material constants $\mu$ and $\alpha$ were determined by a previous in-vitro study [35] and equaled $3.75 \times 10^{-2}$ $\mathrm{MPa}$, and 5.5, respectively. Isotropic linear elastic material properties were assigned to the bones [36], ligaments [37], cartilages [38], plantar fascia [39], Achilles tendon [33, 40] and flexor tendons [41]. The details of the material parameters used in the foot model are given in Table 1. All 3-D structural components of the model were meshed by linear tetrahedral elements (C3D4) with a maximum edge length of $2.3 \mathrm{~mm}$ determined in previous studies [33]. 


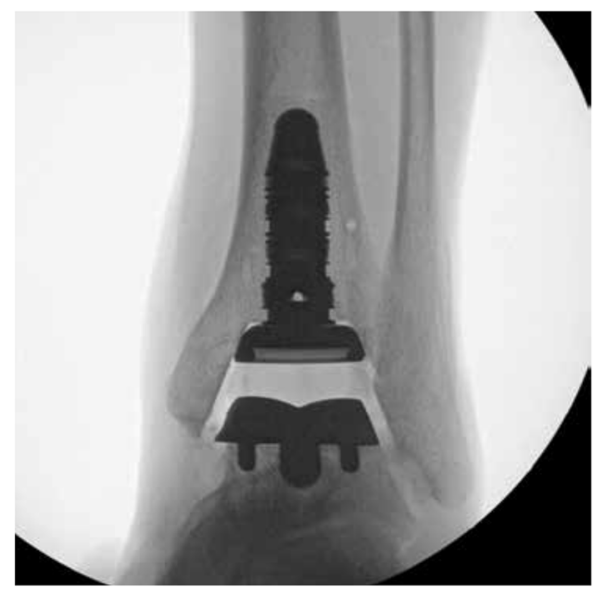

Anterior-Posterior

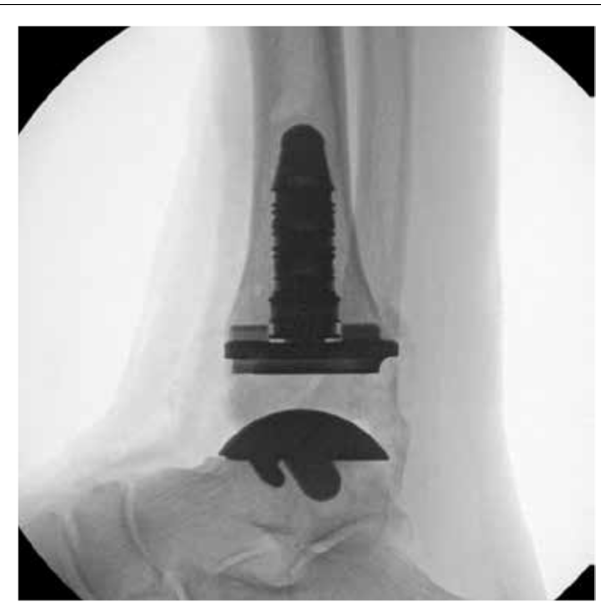

Lateral

Fig. 1 X-ray images of the INBONE II implant system. Intra-operative anterior-posterior and lateral fluoroscopic images of the ankle with INBONE II implant system. (Image courtesy of Wright Medical Technology, Inc., Memphis, TN, US)

Table 1 Material property and element type of the foot model

\begin{tabular}{|c|c|c|c|c|}
\hline & Elastic modulus (MPa) & Poisson ratio & $\begin{array}{l}\text { Cross-sectional area } \\
(\mathrm{mm} 2)\end{array}$ & Element type \\
\hline Bone & 7300 & 0.3 & - & 4-node tetrahedron \\
\hline Cartilage & 1.01 & 0.4 & - & 4-node tetrahedron \\
\hline Ligament & 260 & 0.4 & 18.4 & Spring \\
\hline Plantar Fascia & 350 & 0.4 & - & 4-node tetrahedron \\
\hline Achilles tendon & 816 & 0.3 & - & 4-node tetrahedron \\
\hline Flexor tendon & 450 & 0.3 & 12.5 & Connector \\
\hline Plantar soft tissue & \multicolumn{3}{|c|}{$\begin{array}{l}\text { 1st Ogden incompressive hyperelastic model } \\
\mu=0.0375 \mathrm{MPa}, a=5.5\end{array}$} & 4-node tetrahedron \\
\hline Ground & \multicolumn{3}{|l|}{ Rigid } & 8-node hexahedron \\
\hline
\end{tabular}

\section{TAR implant modeling and implantation}

To match the shape of the current foot model, the INBONE II implant system with a size two long tibial component, a size two polyethylene insert with $6 \mathrm{~mm}$ thickness, and a size two talar component was used. The geometry of this implant system was reconstructed by manual measurement of the dimensions of the implant components retrieved from patients who performed TAR revision surgeries. The standard materials of the tibial component, bearing, and talar component of INBONE II implant system were Ti6Al4V, UHMWPE, and CrCoMo, respectively. The tibia and talus were resected with the protection of the medial malleolus, and this ankle system was implanted following its operative guideline [42] from the manufacturer. The implantation procedure was guided and checked by two senior foot and ankle surgeons (X.M. and X.W.). The mesh size of linear tetrahedral elements for the implant was determined by the mesh convergence test (Supplementary Table S1), which was $1 \mathrm{~mm}$ mesh size at the implant articular surface and $1.5 \mathrm{~mm}$ at the rest of the implant surface.

In this study, four types of materials were used to model tibial and talar components (Ceramic, Co-CrMo, Ti6Al4V, and CFR-PEEK) while three types of materials were used to model the bearing component (CFR-PEEK, PEEK, and UHMWPE). Therefore, the effect of a total of 12 combinations of implant materials was analyzed. To better mimic the biomechanical behavior of UHMWPE material, it was modeled as an isotropic elastic-plastic material [43] with elastic modulus of $556.92 \mathrm{MPa}$, yield stress of $10.86 \mathrm{MPa}$, and Poisson's ratio of 0.46 . The stress-strain curve of the UHMWPE is presented in Fig. 2. The rest of the implant materials were modeled as isotropic elastic materials $[29,44]$, and their mechanical properties are listed in Table 2. And the complete model is illustrated in Fig. 3. 


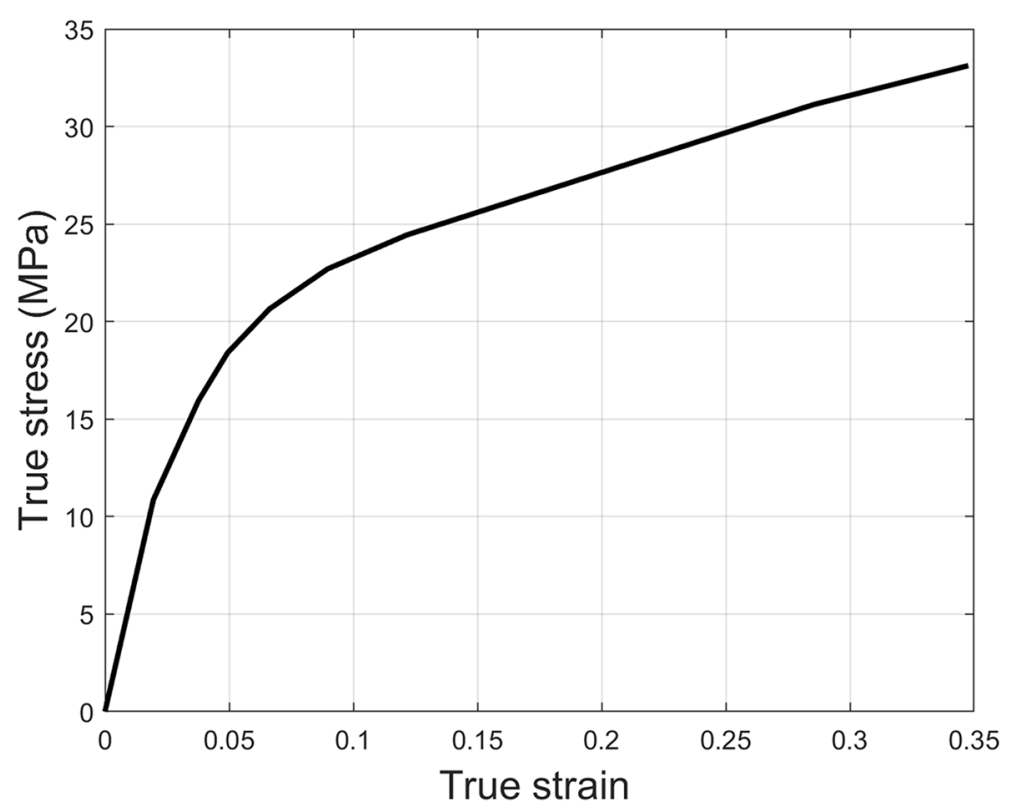

Fig. 2 The stress-strain curve of the UHMWPE material [43]

Table 2 Material property used for implant material modelling

\begin{tabular}{lll}
\hline Implant Material & Elastic modulus (MPa) & $\begin{array}{l}\text { Poisson's } \\
\text { ratio }(\mathbf{v})\end{array}$ \\
\hline Ceramic & 350,000 & 0.26 \\
Co-Cr-Mo & 210,000 & 0.3 \\
Ti6Al4V & 114,000 & 0.342 \\
CFR-PEEK & 18,000 & 0.4 \\
PEEK & 4100 & 0.36 \\
UHMWPE & $556.92 \mathrm{MPa}$ & 0.46 \\
& Stress-strain relationship [43] & \\
\hline
\end{tabular}

\section{Loading and boundary condition}

A finite-sliding surface-to-surface contact behavior was defined to all contact pairs. Normal ("hard" contact with default constraint enforcement method (linear penalty method)) and tangential (penalty or frictionless friction formulation) contact definitions were assigned for interaction properties. ABAQUS automated contact algorithm was used to define contact stiffness and penetration tolerance. A coefficient of friction (COF) of 0.5 was used for the frictional contact interaction between the plantar surface and the ground [33]. The articulation between the bearing and talus was defined as frictionless [31]. The interaction between bone and implant was defined as a tie condition to simulate fully ingrown bones. The tibial tray and bearing component were tied since it is the fix-bearing design.

We analyzed the biomechanical characteristics of the TAR implant at a time when the magnitude of ankle force reached a peak, namely the second peak of the ground reaction forces (GRF) in the normal gait cycle. A rigid plate under the foot was used to model the ground support. The ground was constrained to only allow movement in a vertical direction. The loading condition has previously been established in our foot FE model [33, 34]. In brief, a targeted maximum vertical GRF (623.1 N for the subject with a bodyweight of $60 \mathrm{~kg}$ ) was generated solely by contracting plantar flexors corresponding to the push-off phase in gait. The obtained convergent solution of the muscle forces that maintain the second metatarsal shaft orientation was $1620 \mathrm{~N}$ of GS complex, $267 \mathrm{~N}$ of the TIBP muscle, $130 \mathrm{~N}$ of the FHL muscle, $81 \mathrm{~N}$ of the FDL muscle, $91 \mathrm{~N}$ of the PB muscle, and $193 \mathrm{~N}$ of the PL muscle. Muscle forces of major plantar flexors were applied via the tendons attached. To only investigate the impact of implant material, we assumed all models shared the same boundary and loading conditions.

\section{Data Analysis}

All FE models were solved in ABAQUS (Simulia Corp., Providence, RI, USA). To validate the model by comparison with previously reported data, the plantar pressure and von Mises stress at the implant articular surface of an additional model with the standard materials of INBONE II implant system were simulated. The ankle force was computed by the summation of the magnitude of contact normal force (CNORMF in ABAQUS) of all nodes on the articular surface of the bearing component. For each 


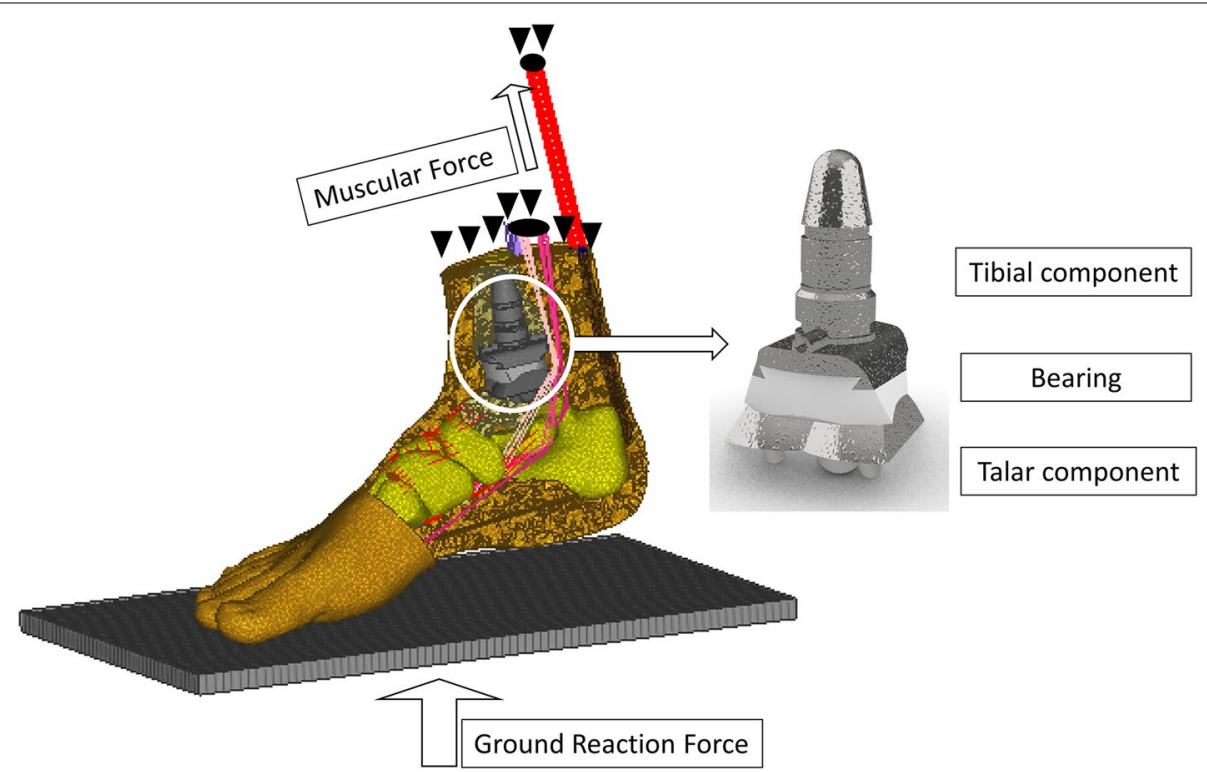

Fig. 3 An illustration of the finite element foot model implanted with INBONE II implant system (Tibial component size: size 2 long. Bearing size: size 2 polyethylene insert with $6 \mathrm{~mm}$ thickness. Talar component size: size 2)

implant material combination, the von Mises stress at the bearing component and the resected surfaces of the tibia and talus were evaluated and compared.

\section{Result}

The plantar pressure of the foot and von Mises stress of the implant articular surface are plotted in Fig. 4. It can be seen that at the second peak of the GRF, plantar pressure concentrates at the forefoot and the plantar surface of the first toe (Fig. 4a). The peak plantar pressure of the INBONE II implanted foot was $0.589 \mathrm{MPa}$, which was similar to that of the foot replaced with STAR total ankle system $(0.605 \mathrm{MPa})$ [12]. The ankle joint typically experiences a higher joint force than the knee and hip joint during the gait, which can reach as much as 5-7 times of body weight $[37,45]$. The total ankle force of the current model was $3463.2 \mathrm{~N}$, which was 5.89 times body weight $(\mathrm{BW})$ and was consistent with the literature. The total lateral force at the articular surface $(1814.9 \mathrm{~N})$ was predicted to be higher than the medial force $(1648.3 \mathrm{~N})$ (Fig. 4b), which was in good agreement with the simulation results of a musculoskeletal modeling study [46].

Comparison of von Mises stress distribution at the resected surface of the tibia for different material combinations

The predicted results of the stress distribution and peak stress value at the resected surface of the tibia for different implant material combinations showed that as the material stiffness of tibial and talar components decreased, the peak stress was largely reduced (66.70 to $82.12 \%$ ) and stress distributed more uniformly (Fig. 5 and Table 3). The stress was insensitive to bearing material stiffnesses (the maximum difference of peak stress value ranged from 0.92 to $6.11 \%$ ).

\section{Comparison of von Mises stress at the top surface of the bearing component for different material combinations}

The predicted results of the stress distribution and peak stress value at the top surface of the bearing component for different implant material combinations showed a general trend that peak stress at the top surface of the bearing component decreased with the stiffness of both the implant and bearing materials, while the stress distributed more evenly (Fig. 6 and Table 4). When the material stiffness of tibial and talar components decreased, the peak stress was slightly decreased (The maximum difference of peak stress value ranged from 6.76 to $24.77 \%$ ). However, as the material stiffness of bearing components decreased, the peak stress was largely reduced (44.76 to $66.95 \%$ ).

\section{Comparison of von Mises stress at the articular surface of the bearing component for different material combinations}

Similar to the top surface, peak stress at the top surface of the bearing component decreased with the stiffness of both the implant and bearing materials (Fig. 7 and Table 5). The maximum stress reduction of changing the material of the bearing component from CFR-PEEK to UHMWPE was 59.79 to $72.77 \%$, while that of changing the material of tibial and talar components was 0.94 to $28.09 \%$. 


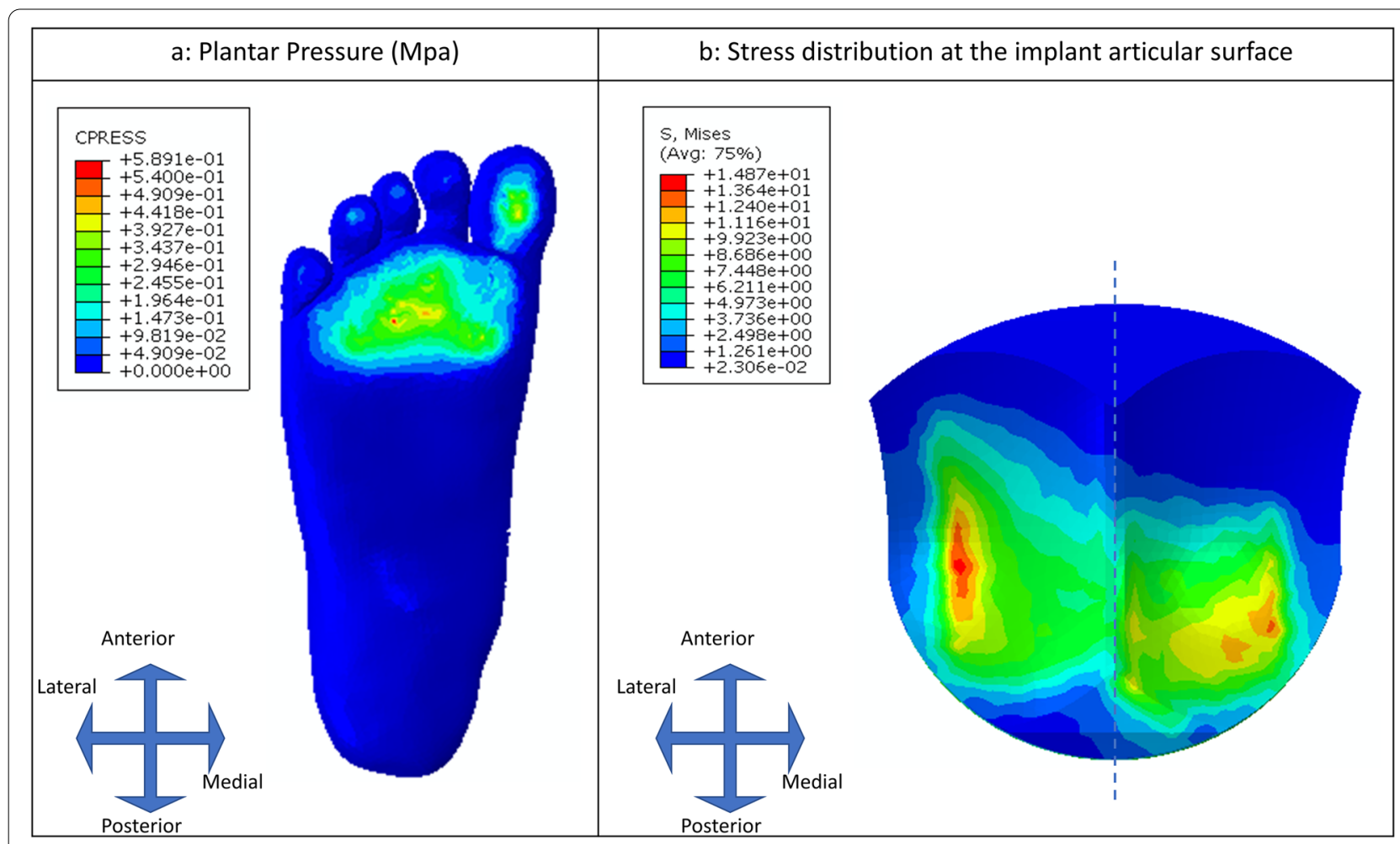

Fig. 4 The plantar pressure of the foot (a) and von Mises stress distribution at the articular surface of the bearing component (b) (Implant material: Ti6AI4V as tibial component material, UHMWPE as bearing material, and $\mathrm{CrCoMo}$ as talar component material)

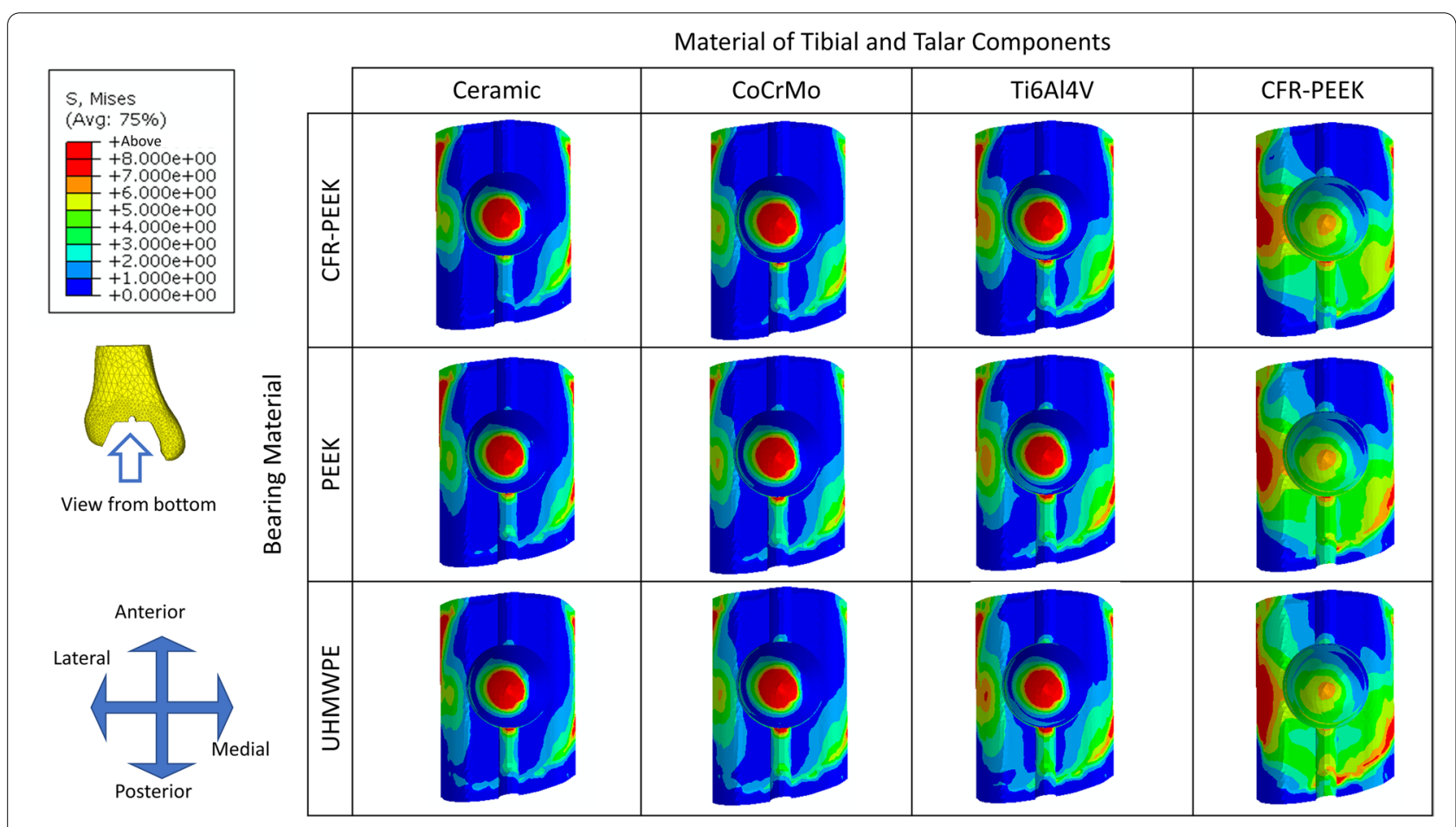

Fig. 5 The von Mises stress distribution at the resected surface of the tibia for different implant material combinations 
Table 3 Peak von Mises stress at the resected surface of the tibia for different implant material combinations

\begin{tabular}{|c|c|c|c|c|c|c|}
\hline \multirow{2}{*}{$\begin{array}{l}\text { Peak von Mises stress } \\
\text { (MPa) }\end{array}$} & & \multicolumn{4}{|c|}{ The material of Tibial and Talar components } & \multirow{2}{*}{$\begin{array}{l}\text { Maximum } \\
\text { difference }\end{array}$} \\
\hline & & Ceramic & CrCoMo & Ti6Al4V & CFR-PEEK & \\
\hline \multirow[t]{3}{*}{ Bearing Material } & CFR-PEEK & 64.21 & 50.92 & 29.91 & 11.4 & $66.70 \%$ \\
\hline & PEEK & 64.23 & 50.86 & 29.84 & 12.12 & $80.59 \%$ \\
\hline & UHMWPE & 63.64 & 50.35 & 29.48 & 11.38 & $82.12 \%$ \\
\hline Maximum difference & & $0.92 \%$ & $1.12 \%$ & $1.44 \%$ & $6.11 \%$ & \\
\hline
\end{tabular}

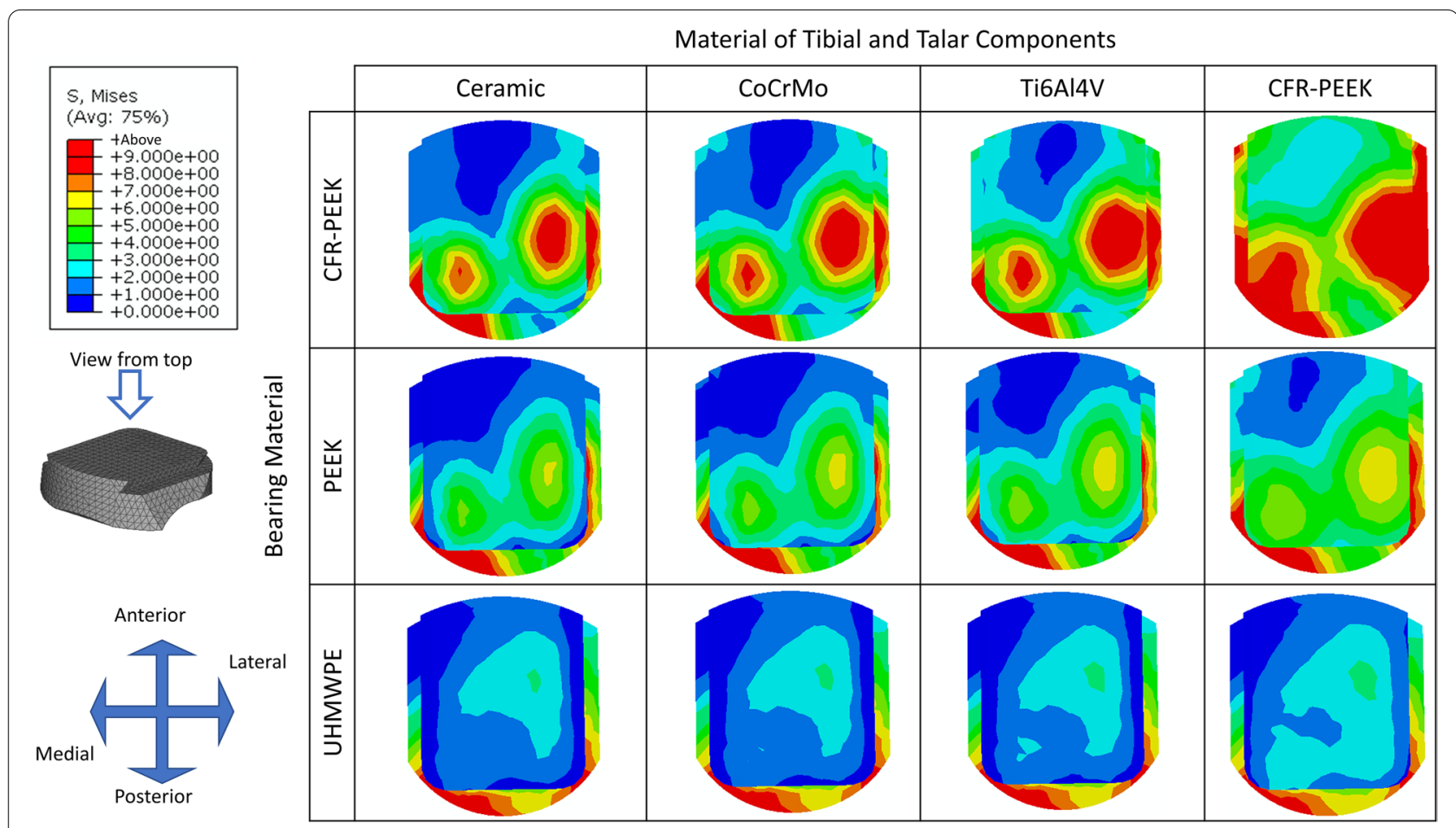

Fig. 6 The von Mises stress distribution at the top surface of the bearing component for different implant material combinations

Table 4 Peak von Mises stress at the top surface of the bearing component for different implant material combinations

\begin{tabular}{|c|c|c|c|c|c|c|}
\hline \multirow{2}{*}{$\begin{array}{l}\text { Peak von Mises stress } \\
(\mathrm{MPa})\end{array}$} & & \multicolumn{4}{|c|}{ The material of Tibial and Talar components } & \multirow{2}{*}{$\begin{array}{l}\text { Maximum } \\
\text { difference }\end{array}$} \\
\hline & & Ceramic & CrCoMo & Ti6Al4V & CFR-PEEK & \\
\hline \multirow[t]{3}{*}{ Bearing Material } & CFR-PEEK & 23.58 & 22.57 & 21.32 & 17.74 & $24.77 \%$ \\
\hline & PEEK & 16.79 & 16.36 & 15.78 & 13.99 & $16.68 \%$ \\
\hline & UHMWPE & 10.51 & 10.46 & 10.32 & 9.80 & $6.76 \%$ \\
\hline Maximum difference & & $55.42 \%$ & $66.95 \%$ & $51.59 \%$ & $44.76 \%$ & \\
\hline
\end{tabular}

Comparison of von Mises stress distribution at the resected surface of the talus for different material combinations

The predicted results of the stress distribution (Table 6) and peak stress value (Fig. 8) at the resected surface of the talus for different implant material combinations showed that as the stiffness of tibial and talar components decreased, the peak stress was slightly reduced. The maximum stress reduction of changing from ceramic to CFR-PEEK ranged from 7.31 to $8.81 \%$. The peak stress was insensitive to bearing stiffnesses (the maximum difference of peak stress value was all less than $5 \%$ ). 


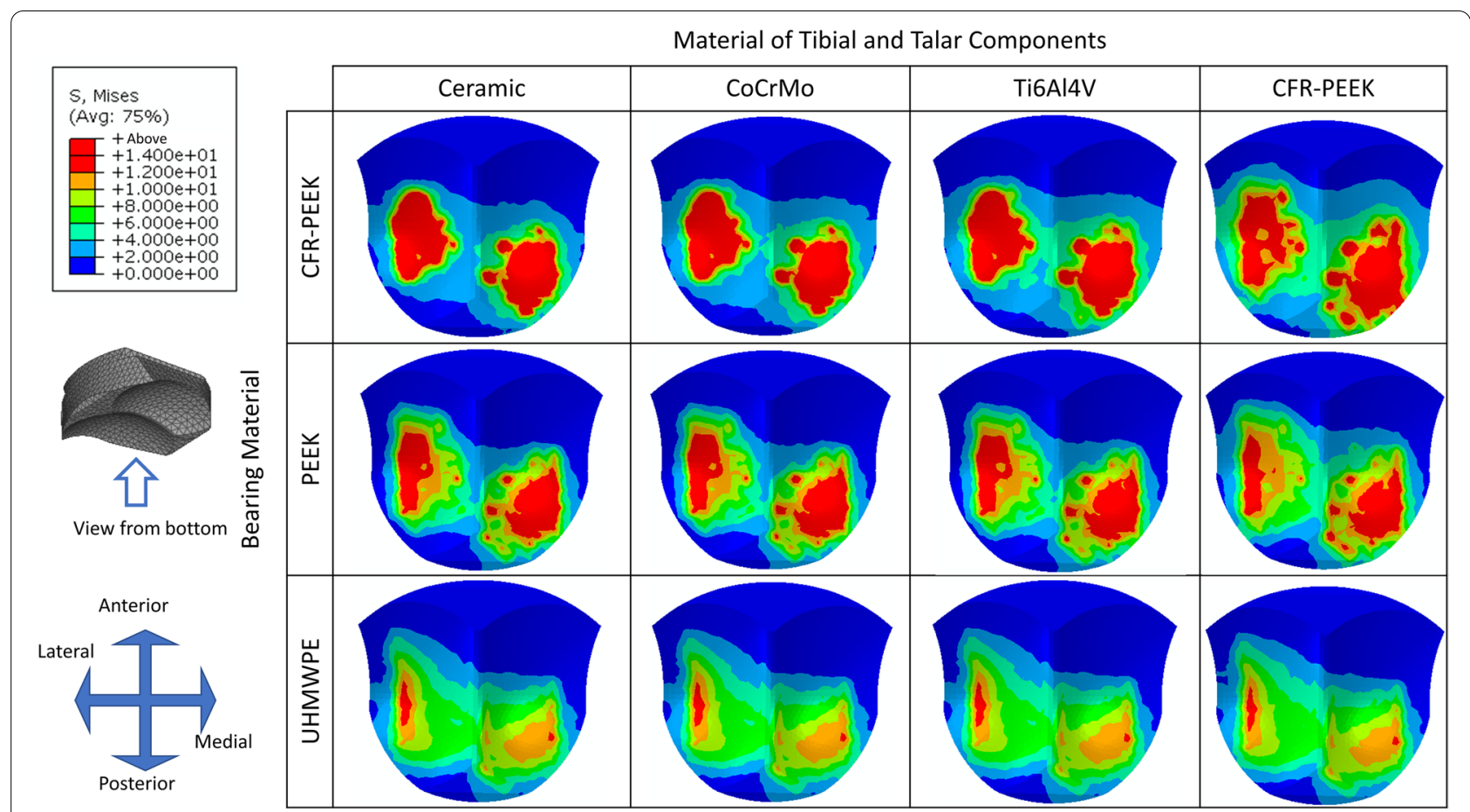

Fig. 7 The von Mises stress distribution at the articular surface of the bearing component for different material combinations

Table 5 Peak von Mises stress at the articular surface of the bearing component for different material combinations

\begin{tabular}{|c|c|c|c|c|c|c|}
\hline \multicolumn{2}{|c|}{ Peak von Mises stress (MPa) } & \multicolumn{4}{|c|}{ The material of Tibial and Talar components } & \multirow{2}{*}{$\begin{array}{l}\text { Maximum } \\
\text { difference }\end{array}$} \\
\hline & & Ceramic & CrCoMo & Ti6Al4V & CFR-PEEK & \\
\hline \multirow[t]{3}{*}{ Bearing Material } & CFR-PEEK & 51.26 & 49.39 & 47.06 & 36.86 & $28.09 \%$ \\
\hline & PEEK & 29.83 & 29.41 & 28.84 & 27.26 & $8.62 \%$ \\
\hline & UHMWPE & 14.96 & 14.92 & 14.86 & 14.82 & $0.94 \%$ \\
\hline \multicolumn{2}{|c|}{ Maximum difference } & $72.77 \%$ & $69.79 \%$ & $68.43 \%$ & $59.79 \%$ & \\
\hline
\end{tabular}

Table 6 Peak von Mises stress at the resected surface of the talus for different implant material combinations

\begin{tabular}{|c|c|c|c|c|c|c|}
\hline \multicolumn{2}{|c|}{ Peak von Mises stress (MPa) } & \multicolumn{4}{|c|}{ The material of Tibial and Talar components } & \multirow{2}{*}{$\begin{array}{l}\text { Maximum } \\
\text { difference }\end{array}$} \\
\hline & & Ceramic & CrCoMo & Ti6Al4V & CFR-PEEK & \\
\hline \multirow[t]{3}{*}{ Bearing Material } & CFR-PEEK & 9.068 & 9.070 & 9.028 & 8.312 & $7.31 \%$ \\
\hline & PEEK & 9.068 & 9.051 & 9.000 & 8.373 & $7.66 \%$ \\
\hline & UHMWPE & 9.415 & 9.271 & 9.101 & 8.586 & $8.81 \%$ \\
\hline \multicolumn{2}{|c|}{ Maximum difference } & $3.69 \%$ & $2.37 \%$ & $1.11 \%$ & $3.19 \%$ & \\
\hline
\end{tabular}

\section{Discussion}

In this study, a comprehensive FE foot model implanted with the detailed geometry of the INBONE II ankle implant was constructed and loading at the second peak of the ground reaction force was simulated. The finite element model with this implant system has not been tested in previous studies.
Twelve implant material combinations were applied to the implant components. The von Mises stress at the top and articular surface of the bearing component and the resected surface of the tibia and talus were analyzed and compared.

Our results revealed that the stress at both the top surface and articular surface of the bearing component can 


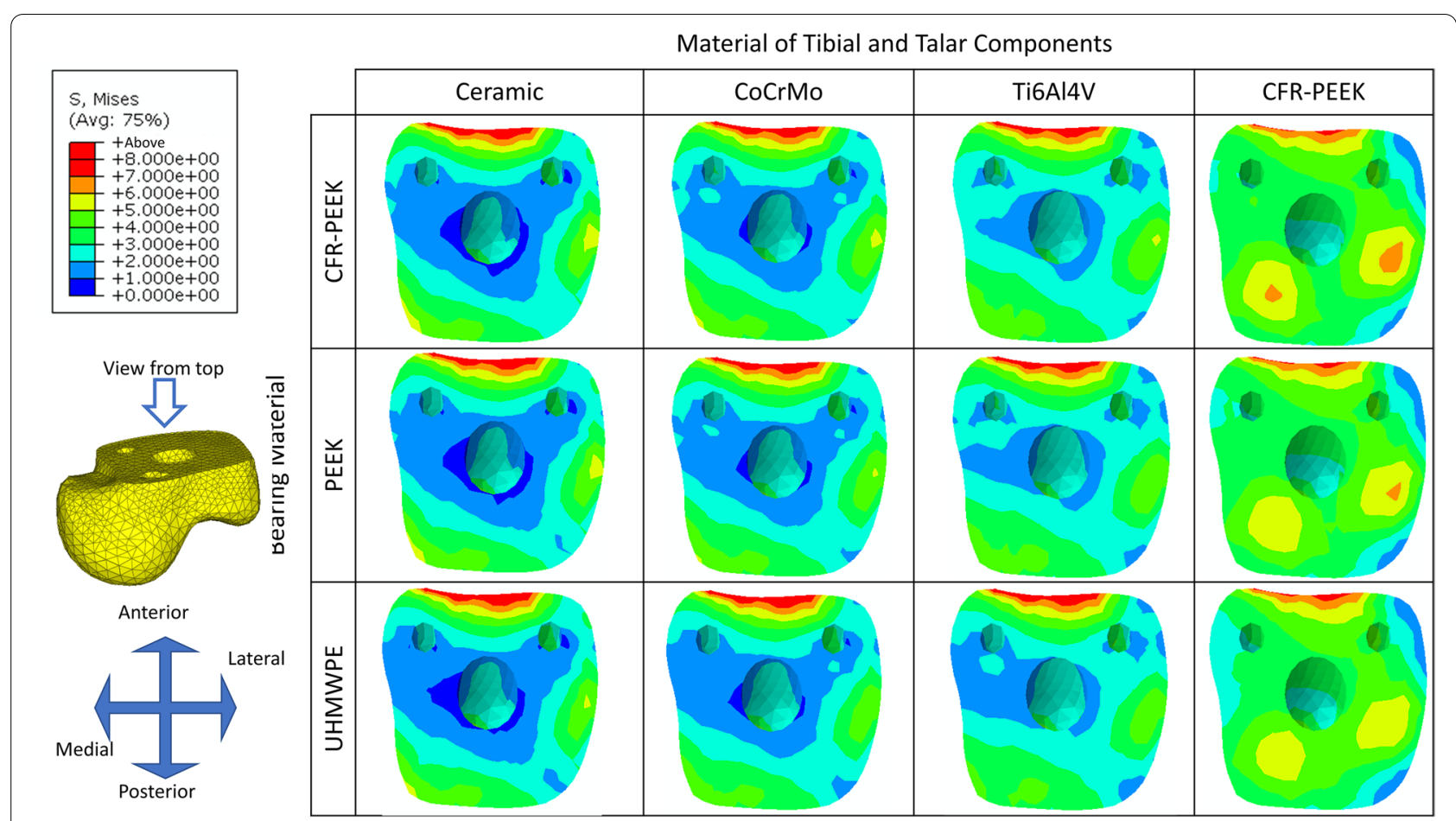

Fig. 8 The von Mises stress distribution at the resected surface of the talus for different implant material combinations

be greatly reduced with more compliant bearing materials (44.76 to $66.95 \%$ and 59.79 to $72.77 \%$ difference of peak von Mises stress value, respectively), and to a lesser extent with more compliant materials for the tibial and talar components ( 0.94 to $28.09 \%$ and 6.76 to $24.77 \%$ difference of peak von Mises stress value, respectively).

Bearing material with UHMWPE showed the lowest peak von Mises stress at the articular surface, which may be one reason why UHMWPE is commonly used as the bearing material. The combination of CFR-PEEK as the material of tibial and talar components and UHMWPE as the bearing material presented the lowest stress of $14.82 \mathrm{MPa}$ at the articular surface, which closely matched the peak stress of the INBONE II implant system with the standard material property $(14.87 \mathrm{MPa})$. However, the peak von Mises stress at the articular surface of bearing component at the second peak of GRF were all above the yield limit provided in the literature [43], which could be one of the reasons that UHMWPE material presents a high wear rate than PEEK and its composites in one simulation study [29]. Although improved manufacturing techniques enabled new UHMWPE material with higher yield stress $[47,48]$. The bearing component with these materials should be further evaluated in wear analyses.

In addition, material change generally made an impact only on the adjacent structure. Peak stresses at the both tibial and talar bone-implant interface could be reduced more strongly by using tibial and talar component materials with smaller material stiffness (44.76 to $66.95 \%$ and 7.31 to $8.81 \%$ difference of peak von Mises stress value, respectively) compared with the bearing material with smaller material stiffness (6.76 to $24.77 \%$ and 1.11 to $3.69 \%$ difference of peak von Mises stress value, respectively). The tibial and talar component with a smaller material stiffness can smooth the stress change across the resected surface of the tibia and talus, thus CFR-PEEK seems to be a good biomechanically alternative to metal components. However, future studies should perform more comprehensive evaluations of the PEEK composite before its application to clinical practice.

The metal-on-metal implant configuration is not considered in this study, since no such arrangement has been used in existing ankle replacement implant systems, and concerns have been raised about its use in hip and knee arthroplasty by researchers [49] and the FDA of United States [50].

One major limitation of the study is that several assumptions were made for simplification, such as applying the fully ingrown conditions at the bone-implant interface without considering implant loosening at the initial stage, no separation of cortical and trabecular bone, neglecting the viscoelastic material property of all structures and the bone remodeling process, and 
simplified contact analysis, which may affect the accuracy of stress prediction, especially at the implant articular surface. What's more, the current foot model was developed from CT images of one healthy volunteer and replaced by one implant model. Future studies should consider using the radiological data of more patients with the surgical implication of TAR. Although the current model was validated for plantar pressure and metatarsal bone strains, further validation of the model in cadaveric or in-vivo studies is still needed. Finally, stress analysis is the first step of the biomechanic study for material selection of TAR implants. Von Mises stresses alone can not fully evaluate the biomechanic performance of TAR implants. A more detailed contact, wear and long-term failure analysis should be included in future studies.

\section{Conclusion}

Implant with smaller material stiffness could provide a stress reduction at both the bearing surfaces and the resected surfaces of the tibia and talus. UHMWPE as the material of the bearing component at the top surface presented the lowest peak value at the top and articular surfaces of the bearing component, while CFR-PEEK as the material of the tibial and talar component exhibited the lowest peak stress value at the resected surface of the tibia and talus. Thus, the selection of CFR-PEEK as the material of tibial and talar components and UHMWPE as the bearing material seemed to be a promising material combination for TAR implant, from the biomechanical perspective. Such results provided insight into the biomechanics of the TAR procedure and material selection of implant components. The FE foot model with the INBONE II implant system can be utilized for further biomechanical investigations of TAR and implant optimization, eventually benefiting patients who need TAR in clinical practice.

\section{Supplementary Information}

The online version contains supplementary material available at https://doi. org/10.1186/s12891-021-04982-3.

Additional file 1: Supplementary Table S1. Sensitivity analysis of the effect of mesh size on the peak stress value (bold mesh size was the mesh size used in this study).

\section{Acknowledgments}

None.

\section{Authors' contributions}

J.Y. and D.Z. contributed equally to this study. J.Y. and D.Z. performed the finite element analysis, drafted the manuscript and designed the figures. D.Z., W.C. and P.C. aided in interpreting the results and worked on the manuscript. S.W. C.Z. and J.H. performed the measurements, X.M. and X.W. were involved in planning and supervised the work. All authors discussed the results and commented on the manuscript. The authors read and approved the final manuscript.

\section{Funding}

This project was supported by National Natural Science Foundation of China (Grant No. 82072388), Natural Science Foundation of Shanghai (Grant No.

19ZR1407400), Clinical Research Plan of SHDC (Grant No. SHDC2020CR3071B).

\section{Availability of data and materials}

The datasets used and analyzed during the current study are available from the corresponding author on reasonable request.

\section{Declarations}

Ethics approval and consent to participate

Not applicable.

\section{Consent for publication}

Not applicable.

\section{Competing interests}

The authors declare that they have no competing interests.

\section{Author details}

${ }^{1}$ Department of Orthopedics, Huashan Hospital, Fudan University, 12 Wulumuqi Zhong Lu, Shanghai 200040, China. ${ }^{2}$ Department of Orthopedics, Ruijin Hospital, Shanghai Jiaotong University, 197 Ruijin Er Lu, Shanghai 200020, China. ${ }^{3}$ Academy for Engineering and Technology, Fudan University, 220 Handan Lu, Shanghai, China.

Received: 6 May 2021 Accepted: 21 December 2021

Published online: 19 January 2022

\section{References}

1. Raikin SM, Rasouli MR, Espandar R, Maltenfort MG. Trends in treatment of advanced ankle arthropathy by total ankle replacement or ankle fusion. Foot Ankle Int. 2014;35(3):216-24.

2. Gougoulias N, Khanna A, Maffulli N. How successful are current ankle replacements?: a systematic review of the literature. Clin Orthop Relat Res. 2010;468(1):199-208.

3. Daniels TR, Younger ASE, Penner M, Wing K, Dryden PJ, Wong H, et al. Intermediate-term results of total ankle replacement and ankle arthrodesis: a COFAS multicenter study. J Bone Joint Surg Am. 2014;96(2):135-42.

4. Lee G-W, Wang S-H, Lee K-B. Comparison of Intermediate to LongTerm Outcomes of Total Ankle Arthroplasty in Ankles with Preoperative Varus, Valgus, and Neutral Alignment. J Bone Joint Surg Am. 2018;100(10):835-42.

5. Clough T, Bodo K, Majeed H, Davenport J, Karski M. Survivorship and long-term outcome of a consecutive series of 200 Scandinavian Total Ankle Replacement (STAR) implants. Bone Joint J. 2019;101-B(1):47-54.

6. Mäkelä KT, Matilainen M, Pulkkinen P, Fenstad AM, Havelin L, Engesaeter $L$, et al. Failure rate of cemented and uncemented total hip replacements: register study of combined Nordic database of four nations. BMJ. Br Med J. 2014;348(f7592).

7. Victor J, Ghijselings S, Tajdar F, Van Damme G, Deprez P, Arnout N, et al. Total knee arthroplasty at 15-17 years: Does implant design affect outcome? Int Orthop. 2014;38(2):235-41.

8. McKenna BJ, Cook J, Cook EA, Crafton J, Knabel M, Swenson E, et al. Total Ankle Arthroplasty Survivorship: A Meta-analysis. J Foot Ankle Surg. 2020:59(5):1040-8.

9. Berlet GC, Brandão RA, Consul D, Ebaugh P, Hyer CF. Short- to Midterm Follow-up of Cemented Total Ankle Replacement Using the INBONE II: A Retrospective Chart Review. Foot Ankle Spec. 2021;14(4):302-11.

10. Rushing CJ, McKenna BJ, Zulauf EA, Hyer CF, Berlet GC. Intermediate-Term Outcomes of a Third-Generation, 2-Component Total Ankle Prosthesis. Foot Ankle Int. 2021;42(7):935-43.

11. Zhao D, Huang D, Zhang G, Wang X, Zhang T, Ma X. Positive and negative factors for the treatment outcomes following total ankle arthroplasty? A systematic review. Foot Ankle Surg. 2020;26(1):1-13. 
12. Wang $Y, L i Z$, Wong DW-C, Cheng C-K, Zhang M. Finite element analysis of biomechanical effects of total ankle arthroplasty on the foot. J Orthopaed Transl. 2018;12:55-65.

13. Taghizadeh Y, Chitsazan A, Pezeshki S, Taghizadeh H, Rouhi G. Total ankle replacement along with subtalar joint arthrodesis: In-vitro and in-silico biomechanical investigations. Int J Numer Methods Biomed Eng. 2021;37(9):e3514.

14. Mondal S, Ghosh R. Effects of implant orientation and implant material on tibia bone strain, implant-bone micromotion, contact pressure, and wear depth due to total ankle replacement. Proc Inst Mech Eng H J Eng Med. 2019;233(3):318-31.

15. Chang B, Brown PR, Sieber A, Valdevit A, Tateno K, Kostuik JP. Evaluation of the biological response of wear debris. Spine J. 2004;4(6):S239-44.

16. Figgie MP, Wright TM, Drinkwater D, Bioengineering Working G. What design and material factors impact the wear and corrosion performance in total elbow arthroplasties? Clin Orthop Relat Res. 2014;472(12):3770-6.

17. Standard Specification forTotal Ankle Replacement Prosthesis: ASTM F2665-09 [S/OL]. [2021-03-01]. (2014).

18. Kurokawa H, Taniguchi A, Morita S, Takakura Y, Tanaka Y. Total ankle arthroplasty incorporating a total talar prosthesis. Bone Joint J. 2019;101-B(4):443-6.

19. Rankin KE, Dickinson AS, Briscoe A, Browne M. Does a PEEK Femoral TKA Implant Preserve Intact Femoral Surface Strains Compared With CoCr? A Preliminary Laboratory Study. Clin Orthop Relat Res. 2016:474(11):2405-13.

20. Koh Y-G, Park K-M, Lee J-A, Nam J-H, Lee H-Y, Kang K-T. Total knee arthroplasty application of polyetheretherketone and carbon-fiber-reinforced polyetheretherketone: A review. Mater Sci Eng C. 2019;100:70-81.

21. Yu J, Zhang C, Chen W-M, Zhao D, Chu P, Wang S, et al. Finite-element analysis of the influence of tibial implant fixation design of total ankle replacement on bone-implant interfacial biomechanical performance. J Orthop Surg. 2020;28(3):2309499020966125.

22. Quevedo Gonzalez FJ, Steineman BD, Sturnick DR, Deland JT, Demetracopoulos CA, Wright TM. Biomechanical evaluation of total ankle arthroplasty. Part II: Influence of loading and fixation design on tibial bone-implant interaction. J Orthop Res. 2021;39(1):103-11.

23. Terrier A, Larrea X, Guerdat J, Crevoisier X. Development and experimental validation of a finite element model of total ankle replacement. J Biomech. 2014;47(3):742-5.

24. Sopher RS, Amis AA, Calder JD, Jeffers JRT. Total ankle replacement design and positioning affect implant-bone micromotion and bone strains. Med Eng Phys. 2017:42:80-90.

25. Mondal S, Ghosh R. Influence of cancellous bone material and dead zone on stress-strain, bone stimulus and bone remodelling around the tibia for total ankle replacement. In: Proceedings of the Institution of Mechanical Engineers, Part H: Journal of Engineering in Medicine; 2020.

26. Mondal S, Ghosh R. The Effects of Implant Orientations and Implant-Bone Interfacial Conditions on Potential Causes of Failure of Tibial Component Due to Total Ankle Replacement. J Med Biol Eng. 2019;39(4):541-51.

27. Mondal S, Ghosh R. A numerical study on stress distribution across the ankle joint: Effects of material distribution of bone, muscle force and ligaments. J Orthop. 2017;14(3):329-35.

28. Mondal S, Ghosh R. Bone remodelling around the tibia due to total ankle replacement: effects of implant material and implant-bone interfacial conditions. Comput Methods Biomech Biomed Eng. 2019:22(16):1247-57.

29. Kerschhofer D, Gundapaneni D, Christof S, Goswami T. Applicability of PEEK and its composites in total ankle replacement devices and wear rate predictions. Biomed Phys Eng Express. 2(2016)065012.

30. Wang Y, Wong DW-C, Tan Q, Li Z, Zhang M. Total ankle arthroplasty and ankle arthrodesis affect the biomechanics of the inner foot differently. Sci Rep. 2019;9(1):13334.

31. Ozen M, Sayman O, Havitcioglu H. Modeling and stress analyses of a normal foot-ankle and a prosthetic foot-ankle complex. Acta Bioeng Biomech. 2013;15(3):19-27.

32. Gross CE, Palanca AA, DeOrio JK. Design Rationale for Total Ankle Arthroplasty Systems: An Update. J Am Acad Orthop Surg. 2018;26(10):353-9.

33. Chen W-M, Park J, Park S-B, Shim VP-W, Lee T. Role of gastrocnemiussoleus muscle in forefoot force transmission at heel rise - A 3D finite element analysis. J Biomech. 2012;45(10):1783-9.
34. Chen W-M, Lee S-J, Lee PVS. Plantar pressure relief under the metatarsal heads - Therapeutic insole design using three-dimensional finite element model of the foot. J Biomech. 2015;48(4):659-65.

35. Chen W-M, Phyau-Wui Shim V, Park S-B, Lee T. An instrumented tissue tester for measuring soft tissue property under the metatarsal heads in relation to metatarsophalangeal joint angle. J Biomech. 2011:44(9):1801-4.

36. Cheung JT-M, Zhang M, Leung AK-L, Fan Y-B. Three-dimensional finite element analysis of the foot during standing - a material sensitivity study. J Biomech. 2005;38(5):1045-54.

37. Siegler S, Block J. The Mechanical Characteristics of the Collateral Ligaments of the Human Ankle Joint. Foot Ankle. 1988;8(5):234-42.

38. Athanasiou KA, Liu LA, Lavery DR, Lanctot RC Jr, Schenck RC Jr. Biomechanical topography of human articular cartilage in the first metatarsophalangeal joint. Clin Orthop Relat Res. 1998;348(0009-921X (Print)):269-81.

39. Wright DC, Rennels DC. A study of the elastic properties fo plantar fascia. jbjs. 1964;46(0021-9355 (Print)):482-92.

40. Wren TAL, Yerby SA, Beaupré GS, Carter DR. Mechanical properties of the human achilles tendon. Clin Biomech. 2001;16(3):245-51.

41. García-González A, Bayod J, Prados-Frutos JC, Losa-Iglesias M, Jules KT, de Bengoa-Vallejo RB, et al. Finite-element simulation of flexor digitorum longus or flexor digitorum brevis tendon transfer for the treatment of claw toe deformity. J Biomech. 2009:42(11):1697-704.

42. INBONE II Total Ankle System SURGICAL TECHNIQUE [www.wrightemed ia.com/ProductFiles/Files/PDFs/016414_EN_HR_LE.pdf].

43. Miller MC, Smolinski P, Conti S, Galik K. Stresses in polyethylene liners in a semiconstrained ankle prosthesis. J Biomech Eng. 2004;126(5):636-40.

44. Manley MT, Ong KL, Kurtz SM. The potential for bone loss in acetabular structures following THA. Clin Orthop Relat Res. 2006:453(453):246-53.

45. Bell CJ, Fisher J. Simulation of polyethylene wear in ankle joint prostheses. J Biomed Mater Res B Appl Biomater. 2007;81 (1):162-7.

46. Zhang Y, Chen Z, Zhao H, Liang X, Sun C, Jin Z. Musculoskeletal modeling of total ankle arthroplasty using force-dependent kinematics for predicting in vivo joint mechanics. Proc Inst Mech Eng H J Eng Med. 2020;234(2):210-22.

47. Standard Specification for Ultra-High-Molecular-Weight Polyethylene Powder and Fabricated Form for Surgical Implant [https://www.astm.org/ Standards/F648.htm].

48. Malito LG, Arevalo S, Kozak A, Spiegelberg S, Bellare A, Pruitt L. Material properties of ultra-high molecular weight polyethylene: Comparison of tension, compression, nanomechanics and microstructure across clinical formulations. J Mech Behav Biomed Mater. 2018:83:9-19.

49. Dunbar MJ, Prasad V, Weerts B, Richardson G. Metal-on-metal hip surface replacement. Bone Joint J. 2014;96-B(11_Supple_A):17-21.

50. Concerns about Metal-on-Metal Hip Implants [https://www.fda.gov/ medical-devices/metal-metal-hip-implants/concerns-about-metal-metalhip-implants].

\section{Publisher's Note}

Springer Nature remains neutral with regard to jurisdictional claims in published maps and institutional affiliations.

Ready to submit your research? Choose BMC and benefit from:

- fast, convenient online submission

- thorough peer review by experienced researchers in your field

- rapid publication on acceptance

- support for research data, including large and complex data types

- gold Open Access which fosters wider collaboration and increased citations

- maximum visibility for your research: over $100 \mathrm{M}$ website views per year

At BMC, research is always in progress.

Learn more biomedcentral.com/submissions 